\title{
Study on the Flexible Practical Education Organization Model for the Cultivation of Engineering Innovation Ability
}

\author{
Shan Zhong ${ }^{1, a}$, Xinmin Zhoü, b, * \\ ${ }^{1}$ Office of Academic Affairs, Wuhan University of Technology, Wuhan430070, China; \\ ${ }^{2}$ School of Automation, Wuhan University of Technology, Wuhan430070, China. \\ azhongshan@whut.edu.cn, *, bzhouxinmin2003@163.com
}

\begin{abstract}
Keywords: Cooperative education between universities and enterprises; System of engineering innovation capabilities cultivation; flexible practical education organization model.
\end{abstract}

\begin{abstract}
Wuhan University of Technology (WUT) is a university with distinct industry characteristics, which take the Excellent Engineer Education Training Program as an opportunity and give full play to the advantages and characteristics of the industry and enterprises, is devoted to deepen cooperative education between universities and enterprises. Thus, cooperative education programs are tactfully linked the industry's demand for innovative talents and personnel training target, WUT has constructed a practical training system and platform for engineering innovation capabilities cultivation, improved the systems of teaching quality assurance and monitoring, and collaborative mechanisms. By implementation of flexible practical education organization model, great progress and achievement have been made in engineering innovation capabilities cultivation of the students who major in experimental specialty of Excellent Engineer Education Training Program, this paper illustrates and details on the implementation of this effective education organization model.
\end{abstract}

\section{Introduction}

With the rapid development of economical society and transformation and promotion of the industry structure, enterprises have put forward higher requirements for engineering education and engineering talents. To promote the transformation of engineering education in China and improve the quality of talents cultivation in engineering education, the Ministry of Education promulgates the Excellent Engineer Education Training Program. This program aims to solve the long-term existence problem about engineering talent cultivation in China. For example, theory is divorced from reality, and production isn't closely related to education. WUT is an important base for talent cultivation and scientific research, which has provided high-level talents cultivation and scientific research services for construction industry, transportation industry and auto industry. WUT focus on improving the students' engineering consciousness, engineering quality and engineering practice ability, it regards practical engineering technology train as the main line, and sets up "for industry, for the future, for the world" engineering education concept, needs the demands of industry and regional economic development.

In the exploration and practice process of strengthening students' innovative ability training based on the Excellent Engineer Education Training Program, WUT has given full play to the advantages and characteristics of the Industry, through the exploration and stage of research (2010-2012), stage of practice improvement (2013-2015) and stage of implementation promotion (2016-2017). Three-stage exploration and pondering, organically connects the industry's demand for innovative talents and professional talents training goals, in-depth cooperate with the three major industries, and proceeding with the construction and implementation of a practical teaching system for the cultivation of students' engineering innovation capabilities and promoting student personality. WUT promotes flexible practical education organization model based on the personalized development needs of students. 


\section{The Significance and Basic Connotation of Strengthening the Cultivation of Students' Engineering Practice Ability}

It is of great practical significance to strengthen engineering students' practical ability training under the new situation. Since it is difficult for the professional and technical personnel trained in current engineering education to adapt to the needs of industry development. The mechanism for collaboratively cultivating talents between universities and industrial enterprises is imperfect, and the support and services for independent learning and personalized development of students are insufficient. The cultivation of engineering students' practical ability in engineering includes emphasis on classroom teaching and light practice education. The training mode for engineering and technical talents adapted to the needs of society is not perfect, the practice teaching link is relatively weak, the necessary engineering training conditions are not available, and the professional teacher team lacks practical engineering experience $[1,2]$. To enhance the engineering practice ability of engineering students, firstly, it is an important way to improve the quality of education and cultivate innovative talents. Secondly, it is necessary to cultivate modern engineers. Thirdly, the urgent need of China's modernization to raise the education of engineering students. The current trend of advanced engineering education in the world. The training of engineering practice ability should be reflected in the training program of engineering major, and it should be implemented in the teaching process. Students are cultivated to discovery problems, analyze problems and solve problems, so that students will not only be able to adapt to the needs of different jobs, but also have the ability to constantly self-renew, self-learn and explore knowledge, they will always be at the forefront of knowledge development with continuous competitiveness [3,4]. WUT has deepen investigation and exchange with construction industry, transportation industry, automotive industry, and elevated the student of the development cross-disciplinary ability, innovative research methods and research capabilities, teamwork and international communication skills, professional qualities and job resilience. The university combines professional advantages and characteristics, with reference to the requirements of the national engineering education professional certification standards and the needs of engineering and technical personnel in the industry's innovation and development, organizes and conducts in-depth discussions to clarify the basic connotations of the industry-related students' engineering innovation capabilities.

\section{The Whole Process of Industry Participation in Engineering Innovation Ability Training Mechanism}

The school combines the training program adjustment in excellent engineering talent training with three major industries of construction, transportation, and autos. In accordance with the principle of combination between theory and practice, knowledge and ability, WUT has established a basic platform and subject for engineering public basic courses and course and professional platform [5]. Relying on the advantages of the three industries, it actively establishes in-depth cooperation with enterprises, and strives to create talents with professional collaboration in the industry training program development, teacher team construction, process organization and implementation. The training mechanism has formed in the five steps coordination talent training, by means of the industry participation in the entire process.

The first is to coordinate the development of personnel training programs and to revise, according to industry needs for innovative talents, to update the training objectives and curriculum system to ensure the social compliance of personnel training; second is to conduct collaborative review of curriculum teaching content, timely introduction of scientific and technological frontiers and business reality Cases, to ensure the effectiveness of curriculum teaching; Third, to coordinate the development of teaching staff to jointly build a combination of teachers and teachers, to jointly cultivate the ability of teachers' engineering practice, ensure the teaching staff of the teaching support; Fourth, the collaborative teaching process organization and The implementation will allow students to gain access to the company's engineering site, gain face-to-face exchanges with corporate 
professional and technical learning opportunities, and improve the relevance of practical teaching; Fifth, to coordinate the quality of teaching monitoring and evaluation, and timely improve the process of the practice teaching system Insufficient to establish a continuous improvement mechanism of the practice teaching system.

\section{The Implementation of Flexible Practical Education Organization Model}

Most of the traditional practice teaching management is based on rigidity, and there are many problems that need to be solved urgently. The experience of engineering education shows that students' adaptability to be separated from the reform and innovation of flexible management system. Therefore, it is imperative to implement flexible and practical teaching management [6]. Flexible personnel training should adopt characteristic education methods to train all kinds of talents. The practice teaching of excellent engineers' pilot professional has always been a top priority in the professional training of students, and the original ruggedized teaching system must be changed to flexible practical education organization model, adapted to the individual development of students [7, 8]. In order to further promote the reform of engineering education, effectively improve the quality of school personnel training and the ability of student services in the three major industries, WUT have selected professional talents in 28 close-knit service industries such as inorganic non-metallic materials, marine engineering, vehicle engineering, and mechanical and electrical engineering. Into the pilot program of the outstanding engineers' education training program, in accordance with the pilot advancement, gradual promotion principle, highlight the depth of cooperation education between universities and enterprises, and begin to practice the construction of practical teaching system for students' ability to innovate and practice.

\subsection{Construction of the Open Practice Education System.}

In accordance with the practical teaching methods of combination of theoretical teaching and practical training, in-class training and extra-curricular practice, and scientific and technological innovation and entrepreneurial practice, WUT has established basic discipline training, professional skills training, production practice training, vocational skills training and innovation. The practical education system aims to enhance entrepreneurial ability training, three styles combinations, five layers levels shows in Figure 1. Innovation ability and professional ability training integrate into the teaching process to form a complete training system for students' engineering innovation ability cultivation.

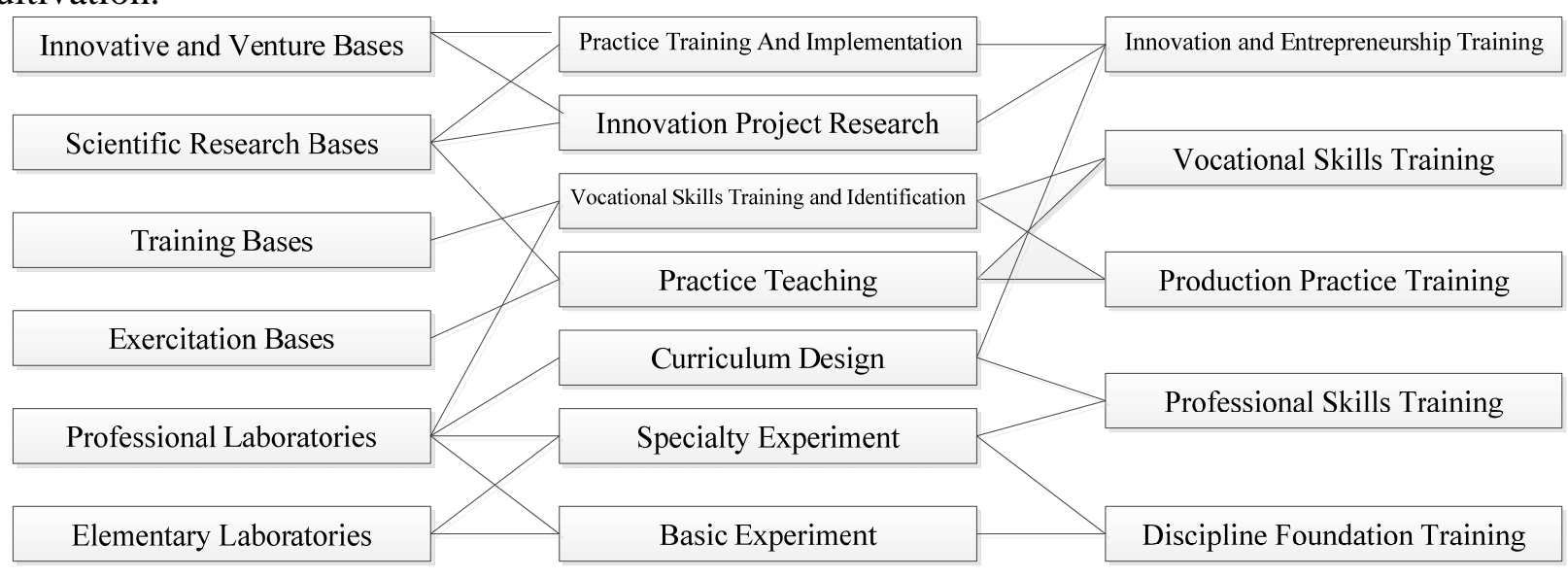

Figure 1. The Open Practice Education System

Based on basic discipline skills training, students are trained to master basic discipline and practical skills. Professional skills training is mainly based on professional experiments, students' professional skills and professional abilities cultivation combining curriculum design and graduation design. Production practical training is mainly based on professional internships, post internships and graduation internships. Through the production practice training both in and outside the school's practice bases, students' abilities and qualities in comprehensive application of professional 
knowledge and skills are improved. Vocational skills training through in-class and out-of-class education fosters students' qualifications and literacy which are necessary for employment in the industry; innovation and entrepreneurship training is based on extracurricular practice, students' innovation awareness, entrepreneurial awareness, and entrepreneurial skills are cultivated through innovative research projects, entrepreneurship training programs, and entrepreneurial practice programs.

\subsection{Practical Teaching Platform Construction Based on Multi-Channel Ways.}

At this stage, due to the enlargement and continuous production of the enterprises, and strict enterprise management and technical confidentiality, the enterprises lack enthusiasm for accepting students' internships. Even if students are practical trained, it is difficult to provide opportunities for students to practical operate in the production line, students cannot intuitively understand the actual process of production and the internal structure of production equipment and production equipment. This has affected the practical effect of the internship to some extent. In order to make up for deficiencies of the practice bases outside school in training students' practical abilities, it has become increasingly necessary to establish on-campus internship bases closely related to engineering theory and engineering practice such as engineering operation [9].

According to the needs of internships, students participate in training and experiments in the professional program for outstanding engineers, WUT has set up an engineering and professional training platform, a public and professional foundation. A school comprehensive innovative practice education platform is built based on practical platform and the school scientific research experiment platform to meet the needs of teaching. The school focuses on the needs of students' ability to innovate in engineering, based on the principles of discipline integration and open sharing, builds a public basic practice platform, a comprehensive experiment and training platform for materials, chemicals, transportation, automotive and mechanical and electrical engineering, and a virtual simulation experimental training teaching platform, sharing rich virtual experimental resources. National-level key laboratories, engineering centers, and other high-level laboratories and research bases are all open to undergraduates, providing good support for undergraduates in carrying out graduate design, innovative research, and practical activities.

At the same time, the school actively expands the off-campus joint training platform. It has a construction, transportation, and automotive industry board of directors based, universities and enterprises have established in-depth development of school-enterprise joint laboratories and talent training centers. Through the cooperation with enterprises and institutions, a national-level engineering practice education center, a provincial demonstration training practice base for universities in Hubei province, and a joint training ground for school-enterprise talents have been jointly established. A base leading group and working group have been set up to form an effective working mechanism, specify planning, organize and implement the professional engineer's pilot professional engineering task. Practical education bases at all levels have provided strong supports for students' practice and innovation.

\subsection{A Collaborative Talent Training Model between Science and Education.}

To realize the training goal of excellence for engineers and research-oriented engineering talents, the school promotes the opening of scientific research bases to the Excellence Education Program, gives full play to the advantages of personnel and facilities for scientific research bases, and makes use of the school's scientific research bases and the conditions for close contact with companies for excellence talent training service, which establishes a talent training model for collaboration between science and education, and allows students to enter the teacher's project team according to their own learning needs, and completes the post-practice teaching goals within the scope of the instructor's arrangement and for a longer period of time (one semester or more).

The school further promotes the opening of high-level scientific research bases for undergraduates, supports research base teachers to convert scientific research projects and achievements into corresponding courses and experimental projects, starts classes for all students, and relies on scientific research projects to design innovative practice training topics suitable for undergraduates and accepts undergraduate courses. Students enter research laboratories for research and training, and 
the laboratories for graduation design thesis rely on scientific research projects to design undergraduate graduation design topics. The school's 4 national-level key laboratories and engineering centers and 23 provincial and ministerial-level scientific research bases offer scientific inquiry courses and experiments for undergraduates and accept undergraduates to participate in research on innovation and entrepreneurship training.

\subsection{Diversified Practice Teaching Organization Model.}

In order to effectively organize and implement the practice teaching process for excellent engineers' pilot professional, the school has formulated relevant management methods according to the actual situation of the enterprise and the individual needs of the students, adopting variety of practical teaching modes like the combination of concentration and decentralization, school-enterprise and school-political integration, and on-campus internships.

The first is to improve the combination of centralized and decentralized internships. Each professional excellence program develops practical teaching arrangements according to its own professional characteristics and the size of the company's acceptance of interns and selects the overall model of the excellence program or the decentralized mode of sub-groups to different companies. The second is to promote the construction of engineering practice teaching platform for political school coordination, industry coordination, school-enterprise coordination, and science-teaching collaboration. Build a comprehensive platform for undergraduate internships with government agencies and enterprises, push various kinds of internship positions, and pilots for excellence engineers take full advantage of the favorable conditions for professional construction, discipline construction, and scientific research bases, build practical bases inside and outside schools, and strengthen practical education for implementation the $3+1$ training mode lays the foundation. The third is to combine the different practical needs of students, WUT explores and implements in-school student internships, and sets up research assistant posts for students based on the research work needs of research base projects.

\section{Conclusion}

Through the Board of Directors of the three major industries of construction, transportation, and automobile, WUT has strengthened connection with the three-major industry enterprises, and has given full play to the respective advantages of the enterprises, institutions, scientific research and design institutes and schools to mutual benefit and common development. It has formed the talent training mechanism for the whole industry to participate in the training objectives and requirements, the auditing and teaching organization, the construction and training of the teaching staff, the quality monitoring and evaluation. By implementation of flexible practical education organization model, great progress and achievement have been made in engineering innovation capabilities cultivation of the students who major in experimental specialty of Excellent Engineer Education Training Program, such as the award rate of excellent bachelor's thesis in Hubei Province, the number of academic contests, published papers and patents, overall satisfaction of the employer with regard to talent cultivation.

\section{References}

[1]. Hue Yuan, Shaolin Yu, et al. The recognition and practice of cultivating engineering students' engineering practice ability under the new situation [J]. Higher education exploration, (2007), NO. 02, p. 61-63.

[2]. Ruching Han. Exploration and practice of engineering practice ability [J]. Chinese university teaching, (2009), NO. 06, p.77-79.

[3]. Bing Tan. Discussion on the reform of economics practice teaching system with multi-level, flexible and open economy -- taking the construction of economics of Guangxi province institute of technology as an example [J]. Modern enterprise education, (2011), NO.11, p.187-188. 
[4]. Jaimie Sun, Dan Liu, et al. Research on the flexible practical teaching system of Internet of things engineering based on CDIO [J]. Practical training and practical exploration, (2016), NO.11, p. 73-74.

[5]. Jing Xiao, Kaifeng Zhang. Excellent engineering talents for industry cooperation education [J]. Chinese university teaching, (2015), NO.05, p.42-44.

[6]. Juan Zhang, Lining Wang. Exploration of the management of flexible practical teaching in computer science [J]. China electric power education, (2011), NO.04, p.124-125.

[7]. Hainan Sun, Yangzi Yu, et al. Research on the cultivation mode of flexible talent in communication engineering in applied universities [J]. Journal of Taiyuan college, (2016), NO.01, p.41-44.

[8]. Kiang Zhao, Bang Tan. Construction and practice of the flexible practical teaching system of network engineering specialty [J]. China electric power education, (2012), NO.10, p. 110-111.

[9]. Bing sheng Zhang, Zigong Chen, et al. Construction of engineering practice teaching system [J]. Jiangsu higher education, (2006), NO.01, p.102-104. 